\title{
A Series of Exceptionally Robust Luminescent Coordination Polymers Based on a Bipyridyldicarboxylate Ligand and Rare-Earth-Metal Ions
}

\author{
Liangjun Li, ${ }^{[a, b]}$ Sifu Tang, ${ }^{[a]}$ Xiaoxia Lv, ${ }^{[a, b]}$ Jinjun Cai, ${ }^{[a, b]}$ \\ Chao Wang, ${ }^{[a, b]}$ and Xuebo Zhao*[a]
}

Keywords: Rare earths / Luminescence / Metal-organic frameworks

A series of three-dimensional rare-earth coordination polymers, $\left[\mathrm{M}_{2}(\mathrm{bpdc})_{3}\left(\mathrm{H}_{2} \mathrm{O}\right)_{4}\right](\mathrm{M}=\mathrm{Y}[1], \mathrm{Sm}[2], \mathrm{Eu}[3], \mathrm{Gd}[4]$, Tb [5], Dy [6], Er [7], and Yb [8]) were synthesized by solvothermal reactions of 2,2'-bipyridine-5,5'-dicarboxylate (bpdc) with corresponding metal salts. Single-crystal and powder X-ray diffraction analyses demonstrated that these coordination polymers are isostructural. The carboxyl groups of the bpdc ligand are coordinated to metal ions and the $2,2^{\prime}$ bipyridine moieties are left free due to the preferable affinity of rare-earth metals for oxygen-donor atoms. The adjacent eight-coordinate $\mathrm{MO}_{8}$ cores show dicapped trigonal prismatic environments; they are interconnected by carboxyl groups and are further bridged through the bipyridyl linkers to give quite dense three-dimensional networks. Photoluminescent studies at room temperature reveal intense red and green luminescent emissions for $\mathrm{Eu}^{\mathrm{III}}$ and $\mathrm{Tb}^{\mathrm{III}}$ analogues, respectively. Furthermore, it is noteworthy that bpdc shows an effective antenna effect in sensitizing emissions from $\mathrm{Eu}^{\mathrm{III}}$ and $\mathrm{Tb}^{\mathrm{III}}$ ions. Thermogravimetric analyses demonstrate that these coordination polymers exhibit exceptional thermal stability (decomposing at $T>580{ }^{\circ} \mathrm{C}$ under $\mathrm{N}_{2}$ for compound $\mathbf{1}$ ). Water-resistance measurements of these coordination polymers show excellent hydrothermal stability.

\section{Introduction}

Coordination polymers, also known as metal-organic frameworks (MOFs) or coordination networks, have immerged as promising materials for applications in gas storage ${ }^{[1]} /$ separation, ${ }^{[2]}$ catalysis, ${ }^{[3]}$ luminescence, ${ }^{[4]}$ magnetism, ${ }^{[5]}$ drug delivery, ${ }^{[6]}$ and so on. As a type of organicinorganic hybrid materials, the properties of coordination polymers could be rationally tuned by deliberately selecting the organic or inorganic components. The rare-earth metals are well known for constructing luminescent materials due to their excellent photophysical properties, especially the narrow bandwidth ascribed to the $\mathrm{f}-\mathrm{f}$ transitions. ${ }^{[4 c, 7]}$ Rareearth-metal-based coordination polymers provide alternative choices for light-emitting diode (LED) applications, because the inherent shortcomings of weak intensities caused by spin- and parity-forbidden characteristics in rare-earth ions can be improved by the excitation of metal ions by means of a ligand-to-metal energy-transfer (LMET) mechanism or an antenna effect when coordinated to ligands. ${ }^{[\mathrm{c}, 8]}$ Additionally, on account of their better stability toward

[a] Qingdao Institute of Bioenergy and Bioprocess Technology, Chinese Academy of Sciences, Shandong, 266101, China E-mail: zhaoxb@qibebt.ac.cn http://info.qibebt.cas.cn/hydrogen/7.htm

[b] University of Chinese Academy of Sciences, Beijing, 100049, China

$\square$ Supporting information for this article is available on the WWW under http://dx.doi.org/10.1002/ejic.201301010. heat and solvents than pure organic compounds or inorganic salts, coordination polymers are more acceptable in practical applications. ${ }^{[9]}$ To construct coordination polymers with good luminescent and physicochemical properties, the rational choice of ligands is crucial. Heterocyclic carboxylate ligands are ideal candidates to form luminescent coordination polymers due to their strong UV absorption and the potential to form chelated coordination bonds with rare-earth ions. ${ }^{[10]}$ Among them, 2,2'-bipydrine-5,5' dicarboxylate (bpdc) is a good example that fulfills these demands, and would be expected to be a good candidate to fabricate luminescent coordination polymers. During the last decade, a number of coordination polymers with intriguing structures and fascinating properties have been synthesized and investigated on the basis of this multifunctional ligand. ${ }^{[9,11]}$ Nevertheless, the rare-earth-metal-based coordination polymers constructed from this ligand are still seldom investigated. Kempe et al. synthesized a coordination polymer based on bpdc and $\mathrm{Nd}^{\mathrm{III}}$ ion in the past. ${ }^{[12]}$ However, the studies on analogue coordination polymers based on other rare-earth-metal ions and further investigations on their chemical and photophysical properties were not carried out.

The potentially complicated and volatile environments of practical applications raise the issue of stability for coordination polymers. Although a large number of coordination polymers have been investigated up to now and some of them exhibit great potential to address specific goals, the 
design and synthesis of robust coordination polymers combined with good properties is still a challenge nowadays. ${ }^{[13]}$ Water resistance in particular is a problem that has frustrated most applications of coordination polymers. In this context, though many works have been performed based on rare-earth metals, ${ }^{[14]}$ coordination polymers that possess both excellent photophysical properties and structural robustness are still rare, ${ }^{[\mathrm{bb}, 7 \mathrm{~b}]}$ and it is essential to be further investigated.

In this paper, we report a series of three-dimensional coordination polymers based on 2,2'-bipydrine-5,5'-dicarboxylate (bpdc) and rare-earth ions ( $\mathrm{Y}^{\mathrm{III}}, \mathrm{Sm}^{\mathrm{III}}, \mathrm{Eu}^{\mathrm{III}}, \mathrm{Gd}^{\mathrm{III}}$, $\mathrm{Tb}^{\mathrm{III}}$, Dy ${ }^{\mathrm{III}}, \mathrm{Er}^{\mathrm{III}}$, and $\left.\mathrm{Yb}^{\mathrm{III}}\right)$. The structural characteristics of these coordination polymers have been analyzed on the basis of single-crystal X-ray analysis and powder X-ray diffractions. The solid-state luminescent properties of the $\mathrm{Eu}^{\mathrm{III}}$ and $\mathrm{Tb}^{\mathrm{III}}$ analogues have been studied at room temperature. The thermal and water stability of these coordination polymers have also been investigated.

\section{Results and Discussion}

\section{Synthesis}

The series of coordination polymers $\left[\mathrm{M}_{2}(\mathrm{bpdc})_{3}\left(\mathrm{H}_{2} \mathrm{O}\right)_{4}\right]$ $(\mathrm{M}=\mathrm{Y}$ [1], Sm [2], Eu [3], Gd [4], Tb [5], Dy [6], Er [7], and $\mathrm{Yb}[\mathbf{8}]$ ) were synthesized through the solvothermal reactions of the bpdc ligand and corresponding rare-earthmetal salts (see the Experimental Section). These coordination polymers are isostructural and were obtained under similar conditions. However, this is not the case for the early lanthanide elements such as $\mathrm{Ce}^{\mathrm{III}}$ and $\mathrm{Pr}^{\mathrm{III}}$, in which a phase of formate or a mixture of unknown compounds and formate were obtained. Other attempts for obtaining pure-

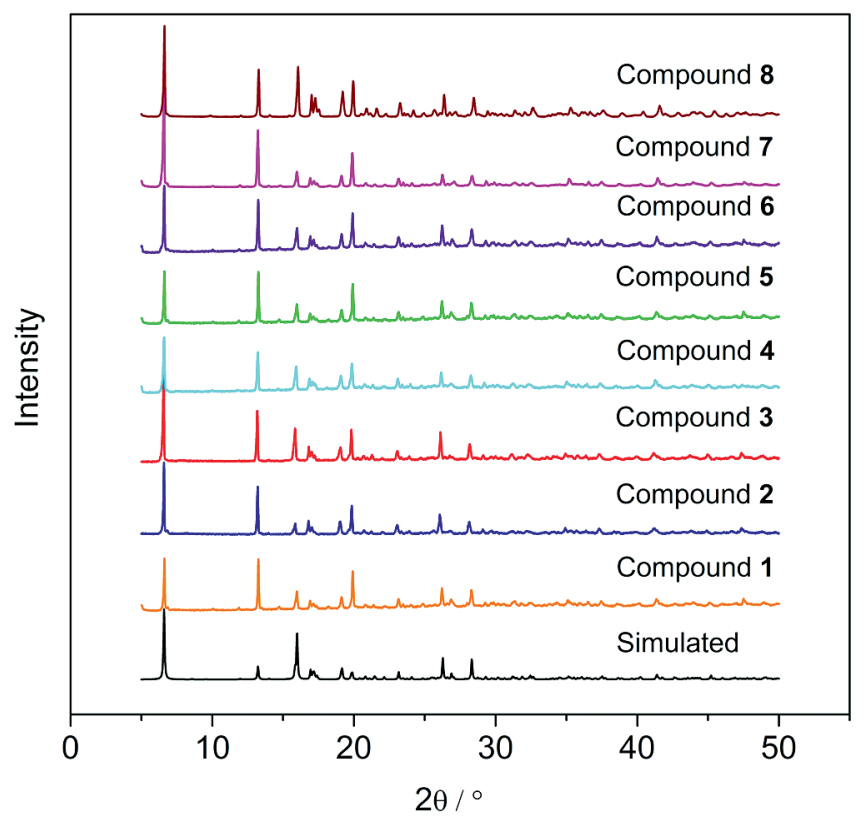

Figure 1. Theoretical and experimental PXRD patterns of the assynthesized samples of compounds 1-8. phase $\mathrm{Ce}^{\mathrm{III}}$ and $\mathrm{Pr}{ }^{\mathrm{III}}$ analogues were proven unsuccessful. Due to the differences throughout the crystallization process, only single crystals of compounds $\mathbf{1}, \mathbf{2}, \mathbf{4}, \mathbf{5}$, and $\mathbf{7}$ could be obtained. The crystal size of compounds $\mathbf{3}, \mathbf{6}$, and 8 was too small to perform the single-crystal X-ray diffractions, but their isomorphic structures and purity were confirmed by powder X-ray diffraction (PXRD) patterns (as demonstrated in Figure 1).

\section{Structural Description}

Single-crystal and powder X-ray diffractions revealed that compounds $\mathbf{1}-\mathbf{8}$ crystallize in a triclinic space group $P \overline{1}$ with the isomorphic structures except for different metal centers. Therefore, only the structure of compound $\mathbf{1}$ is described in detail. The asymmetric unit of compound 1 consists of one-and-a-half bpdc ligands, one crystallographically independent metal ion, and two coordinated water molecules (as shown in Figure 2). The local coordination geometry of the $\mathrm{Y}^{\mathrm{III}}$ ion is an eight-coordinated dicapped trigonal prism, coordinated by six oxygen atoms from five carboxyl groups and two oxygen atoms from two terminal water molecules (as shown in Figures 2 and 3, b). The Y$\mathrm{O}$ bond lengths lie in the range of 2.27-2.47 $\AA$. As seen in Table 1, the metal-oxygen (M-O) bond lengths of these isostructural compounds vary in the range of 2.23-2.51 $\AA$. The $\mathrm{M}-\mathrm{O}$ bond lengths of these compounds are comparable to those reported for other coordination polymers constructed from carboxylate ligands and rare-earth-metal ions, ${ }^{[\mathrm{b}, 10 \mathrm{a}, 15]}$ except for the narrower range of bond lengths that might be attributed to the homogeneous coordination environment of rare-earth-metal ions for these coordination polymers. Except for compound 1, the corresponding $\mathrm{M}_{-}$ $\mathrm{O}$ bond lengths gradually decrease as the atomic number increases, thus indicating the effects of lanthanide contraction. ${ }^{[16]}$

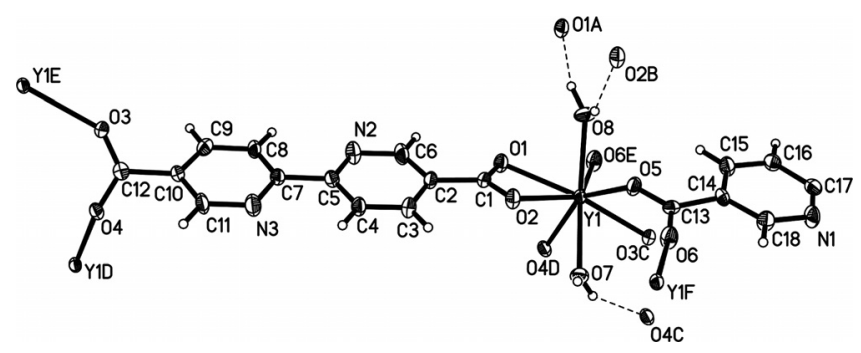

Figure 2. ORTEP diagram of the local environment in compound 1 (thermal ellipsoids: $40 \%$ ). Symmetry operators: A: $-x,-y,-z+$ 1; B: $-x+1,-y,-z+1$; C: $x+1, y+1, z+1$; D: $-x,-y,-z$; E: $x-1, y-1, z-1 ; \mathrm{F}: x+1, y, z$.

Due to the oxophilic nature of rare-earth-metal ions, the carboxyl groups in the ligand are preferably coordinated to metal ions, whereas the 2,2'-bipydrine moieties are left free. This coordination mode is quite different from those formed by the first- or second-row late-transition metals, ${ }^{[9,11 \mathrm{p}]}$ in which both the carboxyl and 2,2'-bipyridine groups are coordinated. Two coordination modes: (syn,synbridging bidentate, chelating bidentate) and bis(syn,syn- 
a)

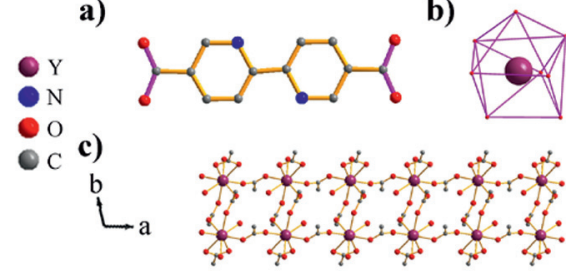

d)

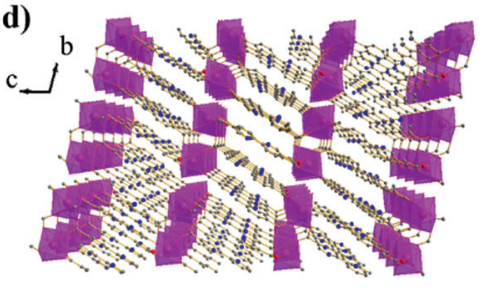

e)

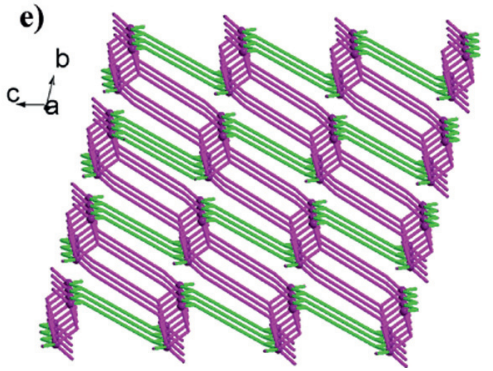

Figure 3. a) Ball-and-stick presentation of the bpdc ligand. b) Coordination geometry of the $\mathrm{YO}_{8}$ polyhedra. c) Presentation of the double chain SBUs viewed from the $c$ axis. d) Packing diagram of

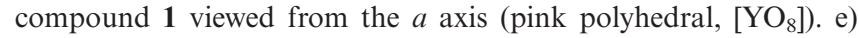
Simplified networks of compound $\mathbf{1}$ viewed from the $a$ axis [bpdc $\mathbf{1}$ and bpdc $\mathbf{2}$ are simplified into 3-connected (in pink) and 4-connected (in green) linkers, respectively. Hydrogen atoms of ligands and coordinated water are emitted for clarity].

Table 1. Selected bond lengths $[\AA]$ for compounds $\mathbf{1}, \mathbf{2}, \mathbf{4}, \mathbf{5}$, and 7. [a]

\begin{tabular}{lccccc}
\hline & $\mathbf{1}(\mathrm{M}=\mathrm{Y})$ & $\mathbf{2}(\mathrm{M}=\mathrm{Sm})$ & $\mathbf{4}(\mathrm{M}=\mathrm{Gd})$ & $\mathbf{5}(\mathrm{M}=\mathrm{Tb})$ & $\mathbf{7}(\mathrm{M}=\mathrm{Er})$ \\
\hline M1-O1 & $2.457(4)$ & $2.506(4)$ & $2.501(2)$ & $2.474(4)$ & $2.452(4)$ \\
M1-O2 & $2.380(3)$ & $2.447(4)$ & $2.421(2)$ & $2.405(4)$ & $2.365(4)$ \\
M1-O3\#3 & $2.382(4)$ & $2.451(4)$ & $2.427(2)$ & $2.411(4)$ & $2.371(4)$ \\
M1-O4\#2 & $2.357(4)$ & $2.425(4)$ & $2.398(3)$ & $2.380(4)$ & $2.335(4)$ \\
M1-O5 & $2.269(4)$ & $2.325(3)$ & $2.309(3)$ & $2.293(4)$ & $2.256(5)$ \\
M1-O6\#1 & $2.240(3)$ & $2.306(4)$ & $2.270(3)$ & $2.264(5)$ & $2.231(4)$ \\
M1-O7 & $2.438(4)$ & $2.507(3)$ & $2.471(2)$ & $2.448(4)$ & $2.416(4)$ \\
M1-O8 & $2.363(4)$ & $2.442(3)$ & $2.378(3)$ & $2.378(4)$ & $2.349(4)$ \\
\hline
\end{tabular}

[a] Symmetry operators for compounds 1, 2, 4, 5, and 7: \#1 $x-1$, $y, z ; \# 2-x,-y,-z ; \# 3 x+1, y+1, z+1$.

bridging bidentate) are observed for bpdc ligands in compound $\mathbf{1}$. To distinguish between them, the ligands that employ these two different coordination modes are named bpdc 1 and bpdc 2, respectively (as shown in Scheme 1). The adjacent $\mathrm{Y}^{\mathrm{III}}$ ions are linked by two carboxyl groups of bpdc 1 in a syn,syn-bridging bidentate mode, thus leading to a dinuclear metal-carboxylate cluster with a $\mathrm{Y}-\mathrm{Y}$ distance of $5.93 \AA$. Then these dinuclear metal-carboxylate clusters are linked together through the carboxyl groups of bpdc 2 in a syn,syn-bridging bidentate mode, thereby resulting in an infinite metal-carboxylate double chain, which can serve as a secondary building unit (SBU) (as shown in

Figure 3, c). These rodlike SBUs are alternatively bridged by bipyridyl linkers of bpdc $\mathbf{1}$ and bpdc $\mathbf{2}$ to give rise to a three-dimensional network (as illustrated in Figure 3, d and e). If bpdc 1 and bpdc 2 are simplified into 3- and 4-connected linkers, respectively, whereas the metal atoms are viewed as 5-connected nodes, then the whole network can be simplified into a topological network illustrated in Figure 3 (e). Calculated by using the TOPOS 4.0 program, ${ }^{[17]}$ the framework can be viewed as a 3-nodal 3,4,5-connected network with Schläfli symbol $\left\{4^{2} \cdot 6\right\}_{2}\left\{4^{2} \cdot 8^{4}\right\}\left\{4^{3} \cdot 6 \cdot 8^{6}\right\}_{3}$. Although two different coordination modes are observed in bpdc ligands, all the bipyridyl rings lie in parallel planes. The different degree of twists for the carboxyl groups with the bipyridyl rings might lead to the different coordination modes of bpdc ligands. The carboxyl groups in bpdc $\mathbf{1}$ exhibit a dihedral angle of about 12.9 and $44.0^{\circ}$ from the bipyridyl ring, whereas the carboxyl groups in bpdc 2 show a very subtle twist from the bipyridyl ring (as illustrated in Figure S2 of the Supporting Information). Three types of hydrogen-bonding interactions from coordination water molecules to carboxylate oxygen atoms are observed in compound 1 (see details in Table S2 of the Supporting Information). These hydrogen-bonding interactions might help strengthen the rigidity and robustness of the network. The self-assembly of bpdc ligands and rare-earth-metal ions in such a manner finally results in a quite dense framework, with the void space close to zero, as indicated by the PLANTON program. ${ }^{[18]}$

a)

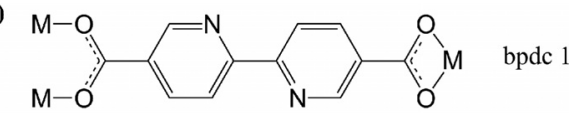

b)

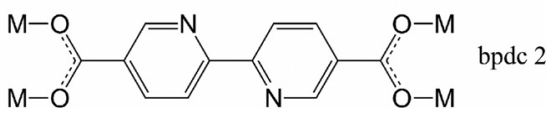

Scheme 1. Two coordination modes for bpdc ligands: (a) bpdc $\mathbf{1}$ (syn,syn-bridging bidentate, chelating bidentate); (b) bpdc 2 bis(syn,syn-bridging bidentate).

\section{Luminescent Properties}

The photoluminescent properties of the bpdc ligand and the as-synthesized samples of compound $\mathbf{3}$ and $\mathbf{5}$ were performed by collecting solid-state excitation and emission spectra at room temperature. As shown in Figure 4 (a), a broad band around $386 \mathrm{~nm}$ is observed in the excitation spectrum of the bpdc ligand. When excited at $386 \mathrm{~nm}$, bpdc emits weak luminescent emissions around 455 and $556 \mathrm{~nm}$, which could be attributed to the $\pi^{*} \rightarrow \pi$ and $\pi^{*} \rightarrow \mathrm{n}$ transitions of the bpdc ligand.

The excitation and emission spectra of compound $\mathbf{3}$ are shown in Figure 4 (b). Upon coordination to $\mathrm{Eu}^{\mathrm{III}}$ ions, a blueshift with the maximum shifts from 386 to $369 \mathrm{~nm}$ was observed. In addition, the characteristic excitation peaks of the $\mathrm{Eu}^{\mathrm{III}}$ ion around 395 and $464 \mathrm{~nm}$ that could be assigned to transitions between ${ }^{7} \mathrm{~F}_{0} \rightarrow{ }^{5} \mathrm{~L}_{6}$ and ${ }^{7} \mathrm{~F}_{0} \rightarrow{ }^{5} \mathrm{D}_{2}$ levels become very weak relative to the broad excitation bands of 

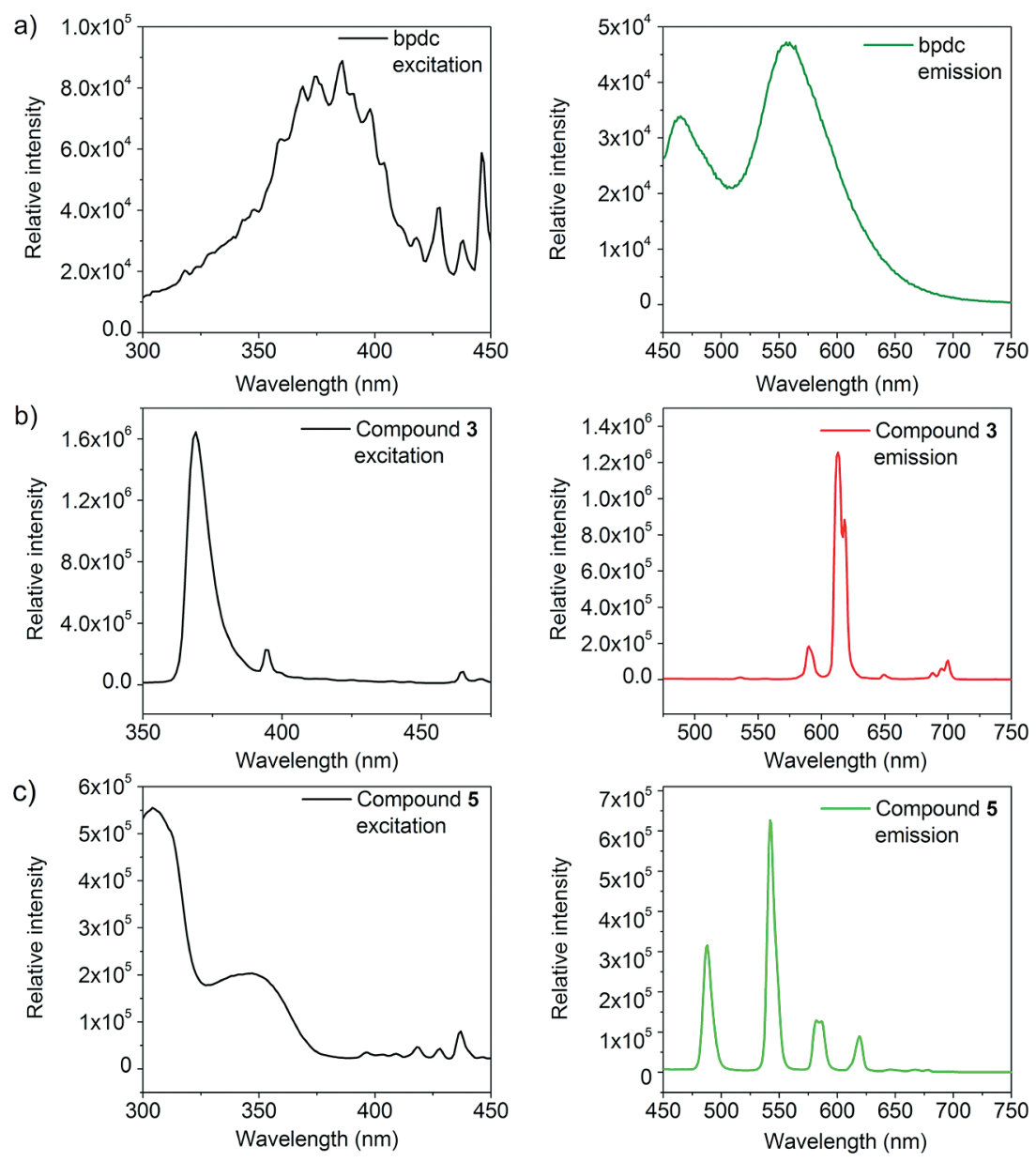

Figure 4. Excitation and emission spectra of (a) bpdc ligand, (b) compound 3, and (c) compound $\mathbf{5}$.

the ligand. The excitation spectrum of compound $\mathbf{3}$ clearly overlaps with the excitation peaks of the bpdc ligand. This phenomenon indicates that the luminescence of $\mathrm{Eu}^{\mathrm{III}} \mathrm{com}-$ plex could be sensitized by means of the excitation of the ligand. Upon excitation at $369 \mathrm{~nm}$, compound 3 emits intense red luminescence. The characteristic emission peaks from bpdc ligands around 455 and $556 \mathrm{~nm}$ disappear, which indicates the effective sensitization of $\mathrm{Eu}^{\mathrm{III}}$ ions from ligand excitation. ${ }^{[19]}$ The emission spectrum exhibits four typical emission peaks around 590, 613, 649, and $700 \mathrm{~nm}$, which are assigned to ${ }^{5} \mathrm{D}_{0} \rightarrow{ }^{7} \mathrm{~F}_{J}(J=1,2,3,4)$ transitions, respectively. ${ }^{[20]}$ It is well known that the intensity ratio between ${ }^{5} \mathrm{D}_{0} \rightarrow{ }^{7} \mathrm{~F}_{2}$ and ${ }^{5} \mathrm{D}_{0} \rightarrow{ }^{7} \mathrm{~F}_{1}$ transitions is strongly relevant to the local symmetry of the Eu ${ }^{I I I}$ ion. Specifically, the transition intensity of ${ }^{5} \mathrm{D}_{0} \rightarrow{ }^{7} \mathrm{~F}_{2}$ increases significantly as the site symmetry of the $\mathrm{Eu}^{\mathrm{III}}$ ion is lowered, whereas the local coordination environment of $\mathrm{Eu}^{\mathrm{III}}$ has no clear impact on the ${ }^{5} \mathrm{D}_{0} \rightarrow{ }^{7} \mathrm{~F}_{1}$ transition. ${ }^{[10 \mathrm{a}, 15]}$ In the emission spectrum of compound 3 , the intensity of the ${ }^{5} \mathrm{D}_{0} \rightarrow{ }^{7} \mathrm{~F}_{2}$ transition is about seven times stronger than the ${ }^{5} \mathrm{D}_{0} \rightarrow{ }^{7} \mathrm{~F}_{1}$ transition, thus indicating that the $\mathrm{Eu}^{\mathrm{III}}$ ion in compound $\mathbf{3}$ is located at a low-symmetric site with no inversion centers, which is in good agreement with $\mathrm{X}$-ray structural analyses.

When coordinated to $\mathrm{Tb}^{\mathrm{III}}$ ions, the excitation spectrum of compound $\mathbf{5}$ shows two broad bands around 305 and
$345 \mathrm{~nm}$. The blueshift $(41 \mathrm{~nm})$ can be ascribed to the larger dihedral angle of the two carboxylic groups in the bpdc ligands, which could reduce the delocalization of electron density from the ligand to the metal and enhance the energy gap between the $\pi-\pi^{*}$ molecular orbital of the bpdc ligand. ${ }^{[21]}$ The characteristic excitation peaks of $\mathrm{Tb}^{\mathrm{III}}$ ions around $360 \mathrm{~nm}$ are completely overlapped by the excitation peaks of the bpdc ligand, thus indicating that the energy transfer from the ligand to metal ion is much more efficient than the direct excitation of $\mathrm{Tb}^{\mathrm{III}}$ ions. ${ }^{[2]}$ Upon sensitization of the $\mathrm{Tb}^{\mathrm{III}}$ ion by means of ligand excitation, compound 5 displays intense green luminescence when excited at $305 \mathrm{~nm}$. Similar to that of compound 3, no ligand-based emission is observed, thereby suggesting good ligand-tometal energy transfer. Four emission bands at 487, 542, 584, and $619 \mathrm{~nm}$ in the emission spectra are attributed to ${ }^{5} \mathrm{D}_{4} \rightarrow{ }^{7} \mathrm{~F}_{J}(J=6,5,4,3)$ transitions, respectively. ${ }^{[20]}$ The spectrum is dominated by a band with maximum around $542 \mathrm{~nm}$, which can be assigned to the hypersensitive transition ${ }^{5} \mathrm{D}_{4} \rightarrow{ }^{7} \mathrm{~F}_{5}$.

\section{Thermal Stability and Water Resistance}

To evaluate the thermal stability of these coordination polymers, thermogravimetric analyses of the bpdc ligand 
and compounds 1-8 were performed under a $\mathrm{N}_{2}$ atmosphere (as shown in Figure 5 (a) and the Supporting information). These coordination polymers exhibit the similar thermogravimetric analysis (TGA) plot patterns, therefore only the TGA plot of compound $\mathbf{1}$ is discussed here in detail. The weight loss of $7.81 \%$ at the first step in the TGA plot of compound $\mathbf{1}$ corresponds to the removal of four coordinated water molecules per unit cell (calcd. 7.38\%). Then, the TGA plot shows a plateau in the temperature range of $235-580^{\circ} \mathrm{C}$, above which the compound begins to decompose. In situ temperature-resolved PXRD patterns were conducted in the temperature range of $25-600{ }^{\circ} \mathrm{C}$ under a $\mathrm{N}_{2}$ atmosphere to validate the thermal stability of compound $\mathbf{1}$. As shown in Figure 5 (b), compound 1 retains its structure up to $550^{\circ} \mathrm{C}$, whereas the crystalline phase was destroyed at $600{ }^{\circ} \mathrm{C}$. This is consistent with the result of the TGA plot, thereby confirming the ultrahigh thermal stability of compound $\mathbf{1}$. The TGA plots of compounds $\mathbf{2}$ $\mathbf{8}$ follow the curve of compound $\mathbf{1}$ except for the different decomposition temperature of compound 1. (The decomposition temperatures of compounds $\mathbf{2 - 8}$ lie in the range of $520-580{ }^{\circ} \mathrm{C}$.) The lower decomposition temperature of compounds 2-8 might result from the longer $\mathrm{M}-\mathrm{O}$ bond length in these compounds. As shown in TGA curves, these compounds do not decompose completely at $800{ }^{\circ} \mathrm{C}$ and exhibit different weight losses at $800^{\circ} \mathrm{C}$. Such differences might be induced by the different degree of decomposition for these compounds or by the formation of carbon materials, thus indicating that the atomic structure of rare-earth-metal ions has some effect on the binding strength as well as the robustness of these compounds. The decomposition temperatures of $520-580^{\circ} \mathrm{C}$ for these coordination polymers are comparable to the most thermally stable coordination polymers. ${ }^{[23]}$ Such an unusual property allows this series of compounds to be rare examples of coordination polymers with exceptional thermal stability. It is commonly believed that the oxophilic nature and high coordination numbers of rare-earth-metal ions could provide coordination polymers with high thermal stabilities. ${ }^{[7 b, 24]}$ In this work, the assembly modes of the bpdc ligand with rare-earth-metal ions have a profound effect on the overall rigidity and the stability of these coordination polymers. Other than the effect of the oxophilic nature and high coordination numbers of rare-earth atoms, the special double-chain SBUs coupled with the dense network might also contribute to the exceptional thermal stability of these coordination polymers.

Besides thermal stability, the resistance against moisture is also a crucial aspect for practical utilizations. To examine the water resistance of these coordination polymers, compounds $\mathbf{3}$ and $\mathbf{5}$ were chosen as representatives for investigation. The as-synthesized samples of compounds $\mathbf{3}$ and $\mathbf{5}$ were first dried in air, and then were stirred in boiling water for $72 \mathrm{~h}$. Then, they were filtered and dried in air again. The structural and crystalline characteristics of the hydrothermally treated samples were examined by collecting PXRD patterns. As shown in Figure 5 (c), both coordination polymers retain their structures and crystallinity well after being treated under hydrothermal conditions, thus in-

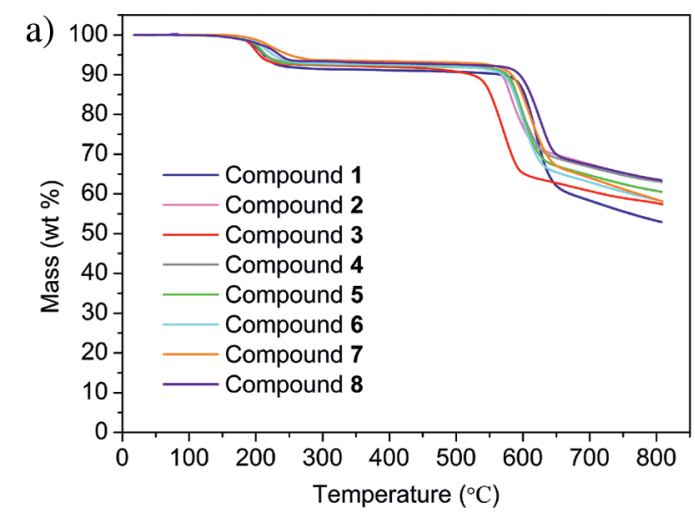

b)

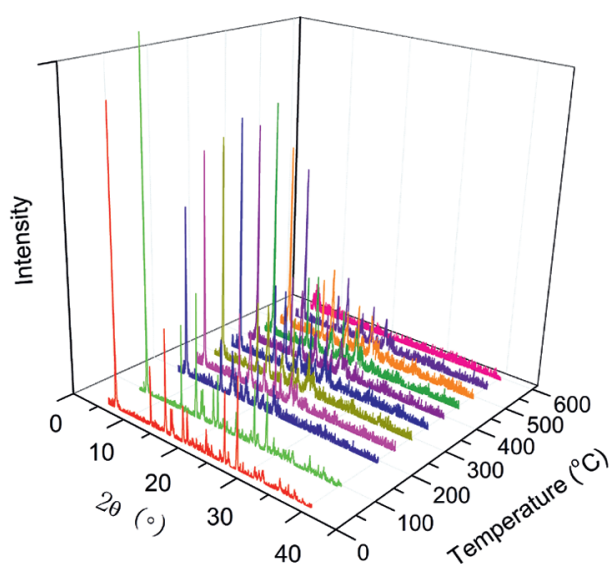

c)

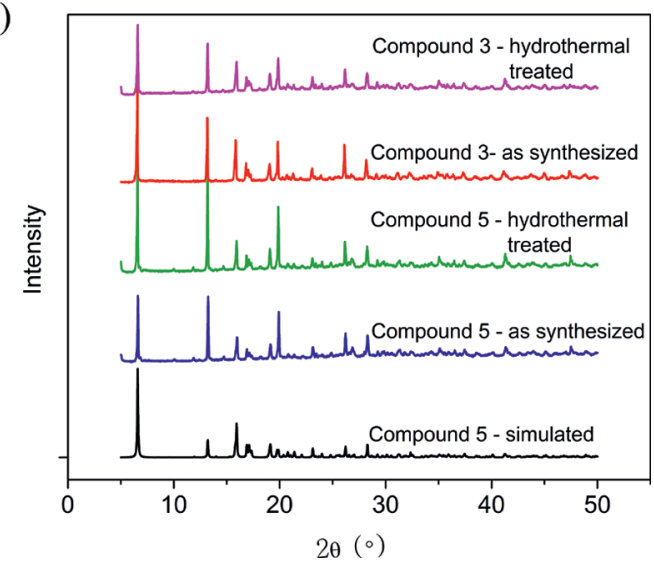

Figure 5. (a) TGA plots of compounds 1-8. (b) Temperature-resolved PXRD pattern of compound 1. (c) PXRD patterns of the as-synthesized and hydrothermally treated samples for compounds 3 and 5.

dicating the excellent water resistance of these coordination polymers. This unusual water-resistant property is of great interest, because the frameworks of most coordination polymers are destroyed by interacting with humidity due to the weakness of coordination bonds. ${ }^{[25]}$ To the best of our knowledge, coordination polymers with exceptional water resistance still remain rare. ${ }^{[13 a, 13 c, 23 c, 26]}$ Therefore, these compounds represent a new type of coordination polymers with exceptional thermal and water stability, thereby ensuring them to be promising materials for practical applications. 


\section{Conclusion}

In summary, a series of isostructural coordination polymers, $\left[\mathrm{M}_{2}(\mathrm{bpdc})_{3}\left(\mathrm{H}_{2} \mathrm{O}\right)_{4}\right](\mathrm{M}=\mathrm{Y}$ [1], Sm [2], Eu [3], Gd [4], $\mathrm{Tb}$ [5], Dy [6], Er [7], and $\mathrm{Yb}$ [8]) based on 2,2'-bipyridine$5,5^{\prime}$-dicarboxylate and rare-earth-metal ions were synthesized and structurally characterized. The self-assembly of the carboxyl groups in bpdc with the eight-coordinate rareearth-metal ions forms double-chain SBUs, which are further bridged by the bipyridyl linkers and result in quite dense three-dimensional networks. Photoluminescent studies reveal intense red and green luminescent emissions for $\mathrm{Eu}^{\mathrm{III}}$ and $\mathrm{Tb}^{\mathrm{III}}$ analogues, respectively. In addition, the bpdc ligand acts as an effective sensitizer for $\mathrm{Eu}^{\mathrm{III}}$ and $\mathrm{Tb}^{\mathrm{III}}$ ions. Thermal and water stability investigations show that these coordination polymers remain stable up to 520 $580^{\circ} \mathrm{C}$ and retain their structures well when treated in boiling water. These ideal photoluminscent properties combined with the exceptional robustness of these coordination polymers make them promising candidates for practical applications.

\section{Experimental Section}

General Information: The rare-earth nitrate hydrates $\mathrm{M}\left(\mathrm{NO}_{3}\right)_{3}$. $x \mathrm{H}_{2} \mathrm{O}(\mathrm{M}=\mathrm{Sm}, \mathrm{Eu}, \mathrm{Gd}, \mathrm{Tb}, \mathrm{Dy}, \mathrm{Er})$ were prepared by dissolving the corresponding rare-earth oxides in an aqueous solution of $\mathrm{HNO}_{3}(6.0 \mathrm{M})$ and then were evaporated at $70{ }^{\circ} \mathrm{C}$. $\mathrm{Y}\left(\mathrm{NO}_{3}\right)_{3} \cdot 6 \mathrm{H}_{2} \mathrm{O}$ and $\mathrm{Yb}\left(\mathrm{NO}_{3}\right)_{3} \cdot 6 \mathrm{H}_{2} \mathrm{O}$ were obtained from Alfa Alesa and used without further purification. The ligand 2,2'-bipyridine-5, $5^{\prime}$-carboxylate was synthesized according to the procedure described in the literature. ${ }^{[11]}$ Other chemicals such as solvents and acid were purchased from J\&K Scientific Ltd. and used as received.

Single-crystal X-ray diffractions of compounds 1, 2, 4, 5, and 7 (Table 2) were performed at room temperature on a BRUKER
SMART APEX2 CCD area detector equipped with graphitemonochromated Mo- $K_{\alpha}$ radiation $(\lambda=0.71073 \AA)$. The programs SAINT $^{[27]}$ and SADABS ${ }^{[28]}$ were employed to carry out the data reductions and adsorption corrections. The structures of the coordination polymers were solved by direct methods using the SHELXTL software package. Then the structures were refined by Fourier techniques. Hydrogen atoms on the ligand were located at ideal positions and refined using a riding model, whereas the hydrogen atoms on water molecules were found from the Fourier map and refined in a constrain mode.

PXRD was recorded with a Bruker D8-Focus Bragg-Brentano Xray powder diffractometer equipped with $\mathrm{Cu}-K_{\alpha}$ radiation $(\lambda=$ $1.54 \AA$ ). In situ temperature-resolved PXRD patterns were performed with the same devices equipped with a high-temperature chamber using $\mathrm{Cu}-K_{\alpha}$ radiation. The sample was loaded on a $\mathrm{Pt}$ plate and heated at a rate of $10{ }^{\circ} \mathrm{Cmin}^{-1}$ under a $\mathrm{N}_{2}$ atmosphere. The data were collected in steps of $100{ }^{\circ} \mathrm{C}$ before $200^{\circ} \mathrm{C}$ and steps of $50{ }^{\circ} \mathrm{C}$ in the temperature range of $200-600^{\circ} \mathrm{C}$. TGA was carried out with a Netzsch STA 449F3 unit at a heating rate of $10{ }^{\circ} \mathrm{C} \mathrm{min}^{-1}$ under nitrogen atmosphere. Fourier transform infrared (FTIR) spectra were measured with a Nicolet 6700 FTIR spectrometer under ambient conditions using $\mathrm{KBr}$ disks. $\mathrm{C}, \mathrm{H}$, and $\mathrm{N}$ elemental analyses were performed with a German Elementary Vario EL cube instrument. Solid-state luminescence measurements were performed at room temperature with an Edinburgh FLSP920 steadystate fluorescence spectrophotometer using a Xe900 lamp as light source. To get comparable results, the experimental conditions such as position and power of the excitation and the width of the slit were fixed to the same conditions. The samples used to collect the luminescence signal were of a similar weight.

CCDC-951357 (for 1), -951358 (for 2), -951359 (for 7), -951360 (for 4), and -951361 (for 5) contain the supplementary crystallographic data for this paper. These data can be obtained free of charge from The Cambridge Crystallographic Data Centre via www.ccdc.cam.ac.uk/data_request/cif.

Compound 1 [ $\left.\mathbf{Y}_{\mathbf{2}}(\mathbf{b p d c})_{\mathbf{3}}\left(\mathbf{H}_{\mathbf{2}} \mathbf{O}\right)_{\mathbf{4}}\right]$ : Ligand bpdc (44 $\left.\mathrm{mg}, 0.18 \mathrm{mmol}\right)$ and $\mathrm{Y}\left(\mathrm{NO}_{3}\right)_{3} \cdot 6 \mathrm{H}_{2} \mathrm{O}(46 \mathrm{mg}, 0.12 \mathrm{mmol})$ were mixed in a solution

Table 2. Crystallographic and structure-refinement details for compounds $\mathbf{1 , 2 , 4 , 5}$, and $\mathbf{7}$.

\begin{tabular}{|c|c|c|c|c|c|}
\hline & 1 & 2 & 4 & 5 & 7 \\
\hline Formula & $\mathrm{C}_{18} \mathrm{H}_{13} \mathrm{~N}_{3} \mathrm{O}_{8} \mathrm{Y}$ & $\mathrm{C}_{18} \mathrm{H}_{13} \mathrm{~N}_{3} \mathrm{O}_{8} \mathrm{Sm}$ & $\mathrm{C}_{18} \mathrm{H}_{13} \mathrm{~N}_{3} \mathrm{O}_{8} \mathrm{Gd}$ & $\mathrm{C}_{18} \mathrm{H}_{13} \mathrm{~N}_{3} \mathrm{O}_{8} \mathrm{~Tb}$ & $\mathrm{C}_{18} \mathrm{H}_{13} \mathrm{~N}_{3} \mathrm{O}_{8} \mathrm{Er}$ \\
\hline Formula weight & 488.22 & 549.66 & 556.56 & 558.23 & 566.57 \\
\hline$T[\mathrm{~K}]$ & $296(2)$ & $296(2)$ & $296(2)$ & $296(2)$ & $296(2)$ \\
\hline Crystal system & triclinic & triclinic & triclinic & triclinic & triclinic \\
\hline Space group & $P \overline{1}$ & $P \overline{1}$ & $P \overline{1}$ & $P \overline{1}$ & $P \overline{1}$ \\
\hline$a[\AA]$ & $5.9310(5)$ & $5.9877(9)$ & $5.9617(12)$ & $5.9529(12)$ & $5.9136(8)$ \\
\hline$b[\AA]$ & $10.8092(10)$ & $10.8829(15)$ & $10.842(2)$ & $10.838(2)$ & $10.7764(15)$ \\
\hline$c[\AA]$ & $13.7808(12)$ & $13.822(2)$ & $13.789(3)$ & $13.781(3)$ & 13.7661(19) \\
\hline$a\left[^{\circ}\right]$ & $102.153(7)$ & 102.111(3) & $102.015(4)$ & $102.068(4)$ & 102.221(3) \\
\hline$\beta\left[^{\circ}\right]$ & $93.932(7)$ & $93.686(3)$ & $93.983(4)$ & $93.942(4)$ & $94.215(3)$ \\
\hline$\gamma\left[^{\circ}\right]$ & $101.552(7)$ & $101.147(3)$ & $101.326(5)$ & $101.403(4)$ & $101.383(3)$ \\
\hline$V\left[\AA^{3}\right]$ & $840.51(13)$ & $858.9(2)$ & $849.1(3)$ & $846.7(3)$ & $834.4(2)$ \\
\hline $\mathrm{Z}$ & 2 & 2 & 2 & 2 & 2 \\
\hline$D_{\text {calcd. }}\left[\mathrm{g} \mathrm{cm}^{-1}\right]$ & 1.929 & 2.125 & 2.177 & 2.190 & 2.255 \\
\hline$F(000)$ & 490 & 536 & 540 & 542 & 548 \\
\hline $\begin{array}{l}\text { Reflections collected/ } \\
\text { unique }\end{array}$ & $7131 / 3755$ & $6766 / 2994$ & $6638 / 2936$ & $6584 / 2921$ & $6443 / 2882$ \\
\hline Goodness-of-fit on $F^{2}$ & 1.004 & 1.004 & 0.920 & 0.972 & 0.984 \\
\hline$R_{\text {int }}$ & 0.0643 & 0.0585 & 0.1013 & 0.0455 & 0.0597 \\
\hline $\begin{array}{l}\text { Final } R \text { indices } \\
{[I>2 \sigma(I)]^{[\mathrm{a}]}}\end{array}$ & $\begin{array}{l}R_{1}=0.0583 \\
w R 2=0.1005\end{array}$ & $\begin{array}{l}R_{1}=0.0422 \\
w R 2=0.0723\end{array}$ & $\begin{array}{l}R_{1}=0.0556 \\
w R 2=0.0793\end{array}$ & $\begin{array}{l}R_{1}=0.0314 \\
w R 2=0.0546\end{array}$ & $\begin{array}{l}R_{1}=0.0389 \\
w R 2=0.0621\end{array}$ \\
\hline$R$ indices (all data) $)^{[a]}$ & $\begin{array}{l}R_{1}=0.1094 \\
w R 2=0.1175\end{array}$ & $\begin{array}{l}R_{1}=0.0579, w R 2= \\
0.0766\end{array}$ & $\begin{array}{l}R_{1}=0.0954 \\
w R 2=0.0898\end{array}$ & $\begin{array}{l}R_{1}=0.0410 \\
w R 2=0.0569\end{array}$ & $\begin{array}{l}R_{1}=0.0545 \\
w R 2=0.0656\end{array}$ \\
\hline
\end{tabular}

[a] $R_{1}=\left(\Sigma|| F_{\mathrm{o}}|-| F_{\mathrm{c}} \mid\right) /\left(\Sigma\left|F_{\mathrm{o}}\right|\right) ; w R_{2}=\left\{\left[\Sigma w\left(F_{\mathrm{o}}^{2}-F_{\mathrm{c}}^{2}\right)^{2}\right] /\left[\Sigma w\left(F_{\mathrm{o}}^{2}\right)^{2}\right]\right\}^{1 / 2}$. 
of $\mathrm{DMF} / \mathrm{H}_{2} \mathrm{O}(12 \mathrm{~mL}, \mathrm{v} / \mathrm{v}=1: 1)$. After being stirred at room temperature for $30 \mathrm{~min}$, the mixture was transferred into a Telfon-lined stainless-steel container and then heated at $120^{\circ} \mathrm{C}$ in a programmed oven for $72 \mathrm{~h}$. When cooling to room temperature at a rate of $3{ }^{\circ} \mathrm{Cmin}^{-1}$, a pure phase of pale green crystals was obtained by filtration and then washed with water, yield $60.4 \%$ based on the ligand. The compound was formulated as $\left[\mathrm{Y}_{2}(\mathrm{bpdc})_{3}\left(\mathrm{H}_{2} \mathrm{O}\right)_{4}\right]$ on the basis of single-crystal $\mathrm{X}$-ray diffractions, elemental analysis, and TGA results. $\mathrm{C}_{36} \mathrm{H}_{26} \mathrm{~N}_{6} \mathrm{O}_{16} \mathrm{Y}_{2}$ (976.44): calcd. C 44.28, $\mathrm{H} 2.68, \mathrm{~N}$ 8.61; found C 44.02, H 2.79, N 8.75.

Compounds 2-8 were prepared by means of the same procedure as compound 1, except that the corresponding hydrated lanthanide nitrates were used. Therefore, only the yields and elemental analysis results of these compounds are given below.

Compound 2: $\left[\mathrm{Sm}_{2}(\mathrm{bpdc})_{3}\left(\mathrm{H}_{2} \mathrm{O}\right)_{4}\right]$, yield $69.1 \%$ based on the ligand. $\mathrm{C}_{36} \mathrm{H}_{26} \mathrm{~N}_{6} \mathrm{O}_{16} \mathrm{Sm}_{2}$ (1099.43): calcd. C 39.33, H 2.38, N 7.64; found C 38.96, H 2.55, N 7.78 .

Compound 3: $\left[\mathrm{Eu}_{2}(\mathrm{bpdc})_{3}\left(\mathrm{H}_{2} \mathrm{O}\right)_{4}\right]$, yield $68.82 \%$ based on the ligand. $\mathrm{C}_{36} \mathrm{H}_{26} \mathrm{Eu}_{2} \mathrm{~N}_{6} \mathrm{O}_{16}$ (1102.55): calcd. C 39.22, $\mathrm{H}$ 2.38, $\mathrm{N}$ 7.62; found $\mathrm{C} 39.02, \mathrm{H} 2.56, \mathrm{~N} 7.45$.

Compound 4: $\left[\mathrm{Gd}_{2}(\mathrm{bpdc})_{3}\left(\mathrm{H}_{2} \mathrm{O}\right)_{4}\right]$, yield $69.77 \%$ based on the ligand. $\mathrm{C}_{36} \mathrm{H}_{26} \mathrm{Gd}_{2} \mathrm{~N}_{6} \mathrm{O}_{16}$ (1113.13): calcd. C 38.84, $\mathrm{H}$ 2.35, N 7.55; found $\mathrm{C} 38.37, \mathrm{H} 2.47, \mathrm{~N} 7.81$.

Compound 5: $\left[\mathrm{Tb}_{2}(\mathrm{bpdc})_{3}\left(\mathrm{H}_{2} \mathrm{O}\right)_{4}\right]$, yield $65.97 \%$ based on the ligand. $\mathrm{C}_{36} \mathrm{H}_{26} \mathrm{~N}_{6} \mathrm{O}_{16} \mathrm{~Tb}_{2}$ (1116.48): calcd. C 38.73, H 2.35, N 7.53; found $\mathrm{C} 38.52, \mathrm{H} 2.53, \mathrm{~N} 7.75$.

Compound 6: [ $\left.\mathrm{Dy}_{2}(\mathrm{bpdc})_{3}\left(\mathrm{H}_{2} \mathrm{O}\right)_{4}\right]$, yield $64.1 \%$ based on the ligand. $\mathrm{C}_{36} \mathrm{H}_{26} \mathrm{Dy}_{2} \mathrm{~N}_{6} \mathrm{O}_{16}$ (1123.63): calcd. C 38.48, H 2.33, N 7.48; found C 38.06, H 2.39, N 7.92 .

Compound 7: $\left[\mathrm{Er}_{2}(\mathrm{bpdc})_{3}\left(\mathrm{H}_{2} \mathrm{O}\right)_{4}\right]$, yield $60.5 \%$ based on the ligand. $\mathrm{C}_{36} \mathrm{H}_{26} \mathrm{Er}_{2} \mathrm{~N}_{6} \mathrm{O}_{16}$ (1133.15): calcd. C 38.16, H 2.31, N 7.42; found C 37.87, H 2.43, N 7.86.

Compound 8: $\left[\mathrm{Yb}_{2}(\mathrm{bpdc})_{3}\left(\mathrm{H}_{2} \mathrm{O}\right)_{4}\right]$, yield $58.68 \%$ based on the ligand. $\mathrm{C}_{36} \mathrm{H}_{26} \mathrm{~N}_{6} \mathrm{O}_{16} \mathrm{Yb}_{2}$ (1144.71): calcd. C 37.77, $\mathrm{H}$ 2.29, N 7.34; found $\mathrm{C} 37.57, \mathrm{H} 2.26, \mathrm{~N} 7.42$.

Supporting Information (see footnote on the first page of this article): Crystallographic data and structural representation and IR spectra.

\section{Acknowledgments}

This work was supported by the National Natural Science Foundation of China (NSFC) (grant numbers 21073216 and 21173246) and by the Chinese Academy of Sciences (Hundred-Talent Project, grant KJCX2-YW-W34).

[1] a) M. Eddaoudi, J. Kim, N. Rosi, D. Vodak, J. Wachter, M. O'Keeffe, O. M. Yaghi, Science 2002, 295, 469-472; b) X. Zhao, B. Xiao, A. J. Fletcher, K. M. Thomas, D. Bradshaw, M. J. Rosseinsky, Science 2004, 306, 1012-1015; c) B. Chen, X. Zhao, A. Putkham, K. Hong, E. B. Lobkovsky, E. J. Hurtado, A. J. Fletcher, K. M. Thomas, J. Am. Chem. Soc. 2008, 130, 64116423.

[2] Y. He, S. Xiang, Z. Zhang, S. Xiong, F. R. Fronczek, R. Krishna, M. O'Keeffe, B. Chen, Chem. Commun. 2012, 48, 10856-10858.

[3] A. Dhakshinamoorthy, M. Alvaro, H. Garcia, Chem. Commun. 2012, 48, 11275-11288.

[4] a) Y. Li, S. Zhang, D. Song, Angew. Chem. 2013, 125, 738; Angew. Chem. Int. Ed. 2013, 52, 710-713; b) Z. Guo, H. Xu,
S. Su, J. Cai, S. Dang, S. Xiang, G. Qian, H. Zhang, M. O'Keeffe, B. Chen, Chem. Commun. 2011, 47, 5551-5553; c) Y. Cui, Y. Yue, G. Qian, B. Chen, Chem. Rev. 2011, 112, 11261162 .

[5] a) D.-K. Cao, Y.-Z. Li, L.-M. Zheng, Inorg. Chem. 2007, 46, 7571-7578; b) K. M. L. Taylor, W. J. Rieter, W. Lin, J. Am. Chem. Soc. 2008, 130, 14358-14359.

[6] a) P. Horcajada, C. Serre, M. Vallet-Regí, M. Sebban, F. Taulelle, G. Férey, Angew. Chem. 2006, 118, 6120-6124; b) J. An, S. J. Geib, N. L. Rosi, J. Am. Chem. Soc. 2009, 131, 8376-8377.

[7] a) P. S. Calefi, A. O. Ribeiro, A. M. Pires, O. A. Serra, J. Alloys Compd. 2002, 344, 285-288; b) J.-Y. Wu, T.-T. Yeh, Y.-S. Wen, J. Twu, K.-L. Lu, Cryst. Growth Des. 2006, 6, 467-473; c) M. Hernández-Molina, C. Ruiz-Pérez, T. López, F. Lloret, M. Julve, Inorg. Chem. 2003, 42, 5456-5458; d) J. Cepeda, R. Balda, G. Beobide, O. Castillo, J. N. Fernández, A. Luque, S. Pérez-Yáñez, P. Román, D. Vallejo-Sánchez, Inorg. Chem. 2011, 50, 8437-8451.

[8] Q. Tang, S. Liu, Y. Liu, J. Miao, S. Li, L. Zhang, Z. Shi, Z. Zheng, Inorg. Chem. 2013, 52, 2799-2801.

[9] S. Huh, S. Jung, Y. Kim, S.-J. Kim, S. Park, Dalton Trans. 2010, 39, 1261-1265.

[10] a) G.-L. Law, K.-L. Wong, Y. Y. Yang, Q.-Y. Yi, G. Jia, W.-T. Wong, P. A. Tanner, Inorg. Chem. 2007, 46, 9754-9759; b) J. Cepeda, R. Balda, G. Beobide, O. Castillo, J. Fernández, A. Luque, S. Pérez-Yáñez, P. Román, Inorg. Chem. 2012, 51, 7875-7888.

[11] a) R. C. Finn, J. Zubieta, Inorg. Chem. Commun. 2000, 3, 520524; b) E. Y. Lee, M. P. Suh, Angew. Chem. 2004, 116, 2858 2861; c) C. J. Matthews, M. R. J. Elsegood, G. Bernardinelli, W. Clegg, A. F. Williams, Dalton Trans. 2004, 492-497; d) K. C. Szeto, K. P. Lillerud, M. Tilset, M. Bjørgen, C. Prestipino, A. Zecchina, C. Lamberti, S. Bordiga, J. Phys. Chem. B 2006, 110, 21509-21520; e) K. C. Szeto, K. O. Kongshaug, S. Jakobsen, M. Tilset, K. P. Lillerud, Dalton Trans. 2008, 2054-2060; f) J. Zhao, D. Shi, H. Cheng, L. Chen, P. Ma, J. Niu, Inorg. Chem. Commun. 2010, 13, 822-827; g) A. Kobayashi, H. Hara, S.-i. Noro, M. Kato, Dalton Trans. 2010, 39, 3400-3406; h) E. D. Bloch, D. Britt, C. Lee, C. J. Doonan, F. J. Uribe-Romo, H. Furukawa, J. R. Long, O. M. Yaghi, J. Am. Chem. Soc. 2010, 132, 14382-14384; i) A. J. Blake, N. R. Champness, T. L. Easun, D. R. Allan, H. Nowell, M. W. George, J. Jia, X.-Z. Sun, Nat. Chem. 2010, 2, 688-694; j) H. Hara, A. Kobayashi, S.-i. Noro, H.-C. Chang, M. Kato, Dalton Trans. 2011, 40, 80128018; k) Y.-Z. Tang, Y.-M. Yang, X.-W. Wang, Q. Zhang, H.R. Wen, Inorg. Chem. Commun. 2011, 14, 613-617; 1) C. Wang, Z. Xie, K. E. deKrafft, W. Lin, J. Am. Chem. Soc. 2011, 133, 13445-13454; m) C. Wang, W. Lin, J. Am. Chem. Soc. 2011, 133, 4232-4235; n) H. Cheng, D. Shi, J. Zhao, Z. Geng, L. Chen, P. Ma, J. Niu, Russ. J. Coord. Chem. 2011, 37, 302-308; o) C. Wang, K. E. deKrafft, W. Lin, J. Am. Chem. Soc. 2012, 134, 7211-7214; p) R. C. Finn, J. Zubieta, Solid State Sci. 2002, 4, 83-86; q) M. Gustafsson, J. Su, H. Yue, Q. Yao, X. Zou, Cryst. Growth Des. 2012, 12, 3243-3249.

[12] B. Schoknecht, R. Kempe, Z. Anorg. Allg. Chem. 2004, 630, 1377-1379.

[13] a) P. L. Llewellyn, S. Bourrelly, C. Serre, A. Vimont, M. Daturi, L. Hamon, G. De Weireld, J.-S. Chang, D.-Y. Hong, Y.-K. Hwang, S.-H. Jhung, G. R. Férey, Langmuir 2008, 24, 72457250 ; b) D. Feng, Z.-Y. Gu, J.-R. Li, H.-L. Jiang, Z. Wei, H.C. Zhou, Angew. Chem. 2012, 124, 10453; Angew. Chem. Int. Ed. 2012, 51, 10307-10310; c) P. Nugent, Y. Belmabkhout, S. D. Burd, A. J. Cairns, R. Luebke, K. Forrest, T. Pham, S. Ma, B. Space, L. Wojtas, M. Eddaoudi, M. J. Zaworotko, Nature 2013, 495, 80-84.

[14] a) M. D. Allendorf, C. A. Bauer, R. K. Bhakta, R. J. T. Houk, Chem. Soc. Rev. 2009, 38, 1330; b) J. Rocha, L. D. Carlos, F. A. A. Paz, D. Ananias, Chem. Soc. Rev. 2011, 40, 926.

[15] S. Su, W. Chen, C. Qin, S. Song, Z. Guo, G. Li, X. Song, M. Zhu, S. Wang, Z. Hao, H. Zhang, Cryst. Growth Des. 2012, 12, 1808-1815. 
[16] D. Aguilà, L. A. Barrios, V. Velasco, L. Arnedo, N. AliagaAlcalde, M. Menelaou, S. J. Teat, O. Roubeau, F. Luis, G. Aromí, Chem. Eur. J. 2013, 19, 5881-5891.

[17] V. A. Blatov, IUCr Comp. Commun. Newsl. 2006, 7, 4-38.

[18] A. Spek, J. Appl. Crystallogr. 2003, 36, 7-13.

[19] B. Chen, Y. Yang, F. Zapata, G. Lin, G. Qian, E. B. Lobkovsky, Adv. Mater. 2007, 19, 1693-1696.

[20] a) J.-C. G. Bünzli, S. V. Eliseeva, J. Rare Earths 2010, 28, 824 842; b) J. C. G. Buenzli, G. R. Choppin, Lanthanide Probes in Life, Chemical and Earth Sciences: Theory and Practice, Elsevier, 1989.

[21] Q. Zhu, T. Sheng, C. Tan, S. Hu, R. Fu, X. Wu, Inorg. Chem. 2011, 50, 7618-7624.

[22] S. I. Klink, L. Grave, D. N. Reinhoudt, F. C. J. M. van Veggel, M. H. V. Werts, F. A. J. Geurts, J. W. Hofstraat, J. Phys. Chem. A 2000, 104, 5457-5468.

[23] a) N. Masciocchi, G. A. Ardizzoia, G. LaMonica, A. Maspero, A. Sironi, Eur. J. Inorg. Chem. 2000, 2507-2515; b) S. Y. Yang, L. S. Long, R. B. Huang, L. S. Zheng, Chem. Commun. 2002,
472-473; c) J. H. Cavka, S. Jakobsen, U. Olsbye, N. Guillou, C. Lamberti, S. Bordiga, K. P. Lillerud, J. Am. Chem. Soc. 2008, 130, 13850-13851.

[24] L. Pan, N. Zheng, Y. Wu, S. Han, R. Yang, X. Huang, J. Li, Inorg. Chem. 2001, 40, 828-830.

[25] a) G. D. Pirngruber, L. Hamon, S. Bourrelly, P. L. Llewellyn, E. Lenoir, V. Guillerm, C. Serre, T. Devic, ChemSusChem 2012 , 5, 762-776; b) A. C. Kizzie, A. G. Wong-Foy, A. J. Matzger, Langmuir 2011, 27, 6368-6373.

[26] M. Kandiah, M. H. Nilsen, S. Usseglio, S. Jakobsen, U. Olsbye, M. Tilset, C. Larabi, E. A. Quadrelli, F. Bonino, K. P. Lillerud, Chem. Mater. 2010, 22, 6632-6640.

[27] SAINT, SMART, Bruker, Bruker AXS Inc., Madison, Wisconsin, USA. 2007.

[28] G. M. Sheldrick, $S A D A B S$, University of Göttingen, Germany, 2004.

Received: August 5, 2013

Published Online: November 14, 2013 